\title{
Systematic Review on the Functional Outcome After Treatment of a Traumatic Bowing Fracture of the Lower Arm in Children
}

\section{Linde Musters* and Joost Colaris}

Resident Orthopaedic Surgery Spaarne Gasthuis, location Hoofddorp, Spaarnepoort 1, 2134 TM Hoofddorp, Netherlands

*Corresponding author: Linde Musters, Resident Orthopaedic Surgery Spaarne Gasthuis, location Hoofddorp, Spaarnepoort 1, 2134 TM Hoofddorp, Netherlands, Tel: +31 23224 0000; Fax: 023-2249535; E-mail: lindemusters@gmail.com

Rec date: May 25, 2017; Acc date: July 19, 2017; Pub date: July 21, 2017

Copyright: (c) 2017 Musters L, et al. This is an open-access article distributed under the terms of the creative commons attribution license, which permits unrestricted use, distribution, and reproduction in any medium, provided the original author and source are credited.

\begin{abstract}
Introduction: Traumatic bowing is a commonly missed diagnosis on which only little information is available, inadequate treatment can cause permanent function loss.

Method: A systematic review would determine what the effect is of treatment of traumatic bowing of the lower arm in children on the functional outcome. A search on Embase, Medline, Web of Science, Scopus, Cochrane, Pubmed publisher, CINAHL and Google scholar, last accessed at the 15th of May 2016. Intervention of interest was treatment; with reduction, reduction and cast or cast only. The primary outcome measure was (I) function; pro and supination, (II) posttraumatic function, (III) posttreatment function and (IV) residual bowing.

Results: Five articles were included. Treatment by reduction only showed a normal function, 4 weeks to 8 weeks of cast and reduction followed by cast, both resulted in 0 degrees to 20 degrees residual of pronation loss.

Discussion: The treatment was overall well tolerated, had a direct effect and lead to faster restore of function. It is unclear to what amount of bowing can be accepted without any loss of function. But in view of the few complications and good results for reduction, the overall opinion is to reduce all significant bowing fractures of the lower arm in children with limited function.
\end{abstract}

Keywords: Trauma; Pediatric; Lower arm; Bowing; Plastic deformity

\section{Introduction}

Traumatic bowing of the forearm was described first in 1974 [1]. Traumatic bowing is a commonly missed diagnosis on which only little information is available. However, has long lasting consequences when missed $[1,2]$.

The main reason for this diagnosis to be missed is that there is no fracture line visible on the conventional radiology. Furthermore, this type of fracture does not follow the standard radiographic phases of fracture healing [3]. The available information is based on small series of patients with no long term follow up [2].

The typical trauma mechanism is a fall on an outstretched hand. Patients present with pain, deformity and function loss. The first weeks no evident radiological abnormalities are found, but after five to six weeks some periosteal thickening on the concavity of the bowing can be seen. There is no standardized protocol for bowing fractures of the lower arm in children (Figure 1). There is some consensus in literature about the group under four years and over ten years of age, however, a consensus in the current literature is lacking in the group between four and ten years with the highest prevalence [2].

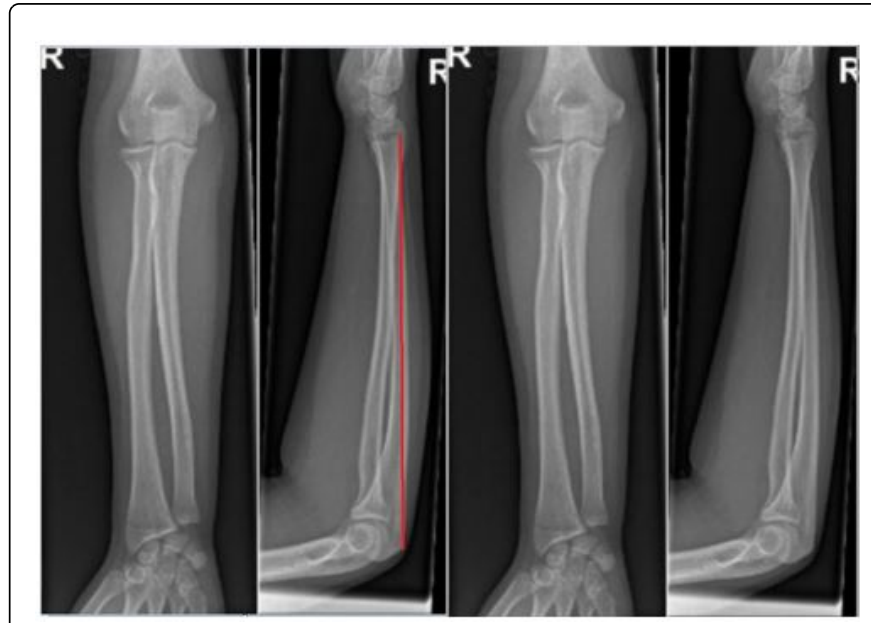

Figure 1: X-ray of the right lower arm post traumatic with a bowing of ulna of 5.6 degrees.

The etiology is well known due to in vitro and in vivo animal research on canine ulnar bones. Bone has a certain elasticity which allows it to bend and restore ('elastic deformity'). However, when the bone is bend over the maximal elasticity (150\% bodyweight), hundreds of micro fractures appear, which lead to irreparable damage with a remaining bowing ('plastic deformity') (Figure 1). This bowing can be 
Citation: Musters L, Colaris J (2017) Systematic Review on the Functional Outcome After Treatment of a Traumatic Bowing Fracture of the

Page 2 of 7

seen on a conventional X-ray, when made in correct anteroposterior/ lateral direction of the wrist and the elbow [1-4].

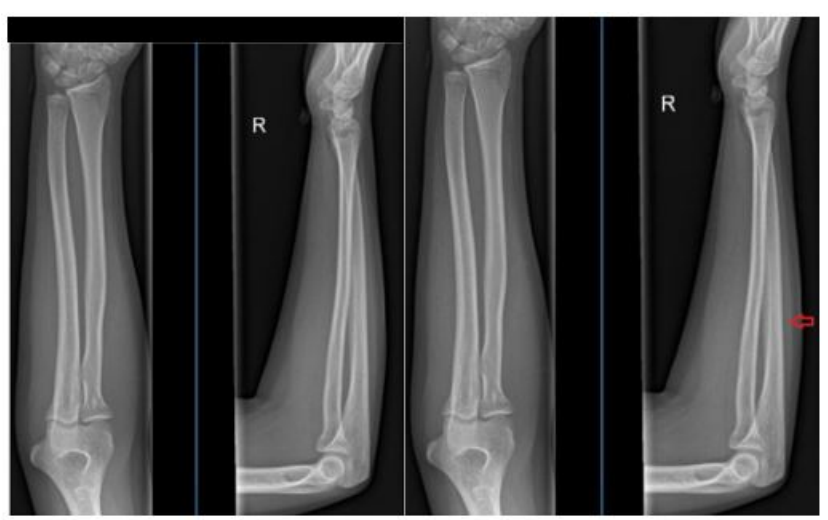

Figure 2: X-ray six weeks post traumatic; slear sign of periostal thickening of the ulna with a bowing of 3.9 degrees.

Currently, the best available measure method for bowing of the radius is the one of Schemitssch an Richards, which has been validated in 2004 by Firl et al. for children (Figure 2). They discuss two different values; $x / y \times 100$ and $r / y \times 100$. The average maximum value of the radius until the maximal bowing independent of age is 60.39 percent $(\mathrm{x} / \mathrm{y} \times 100)$ and the average bowing independent of age is 7.21 percent $(\mathrm{r} / \mathrm{y} \times 100)$, respectively (Figure 3$)$ [5].

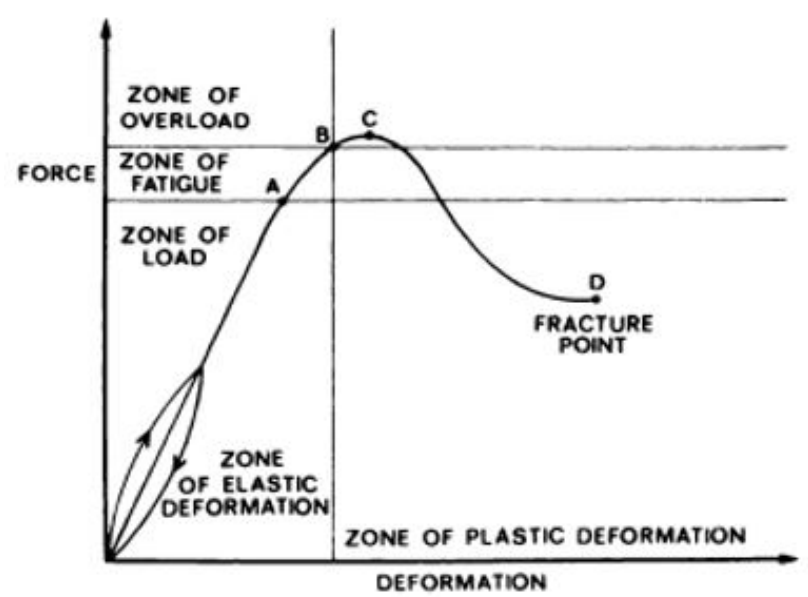

Figure 3: Relation between bowing and force (longitudinal) effect of force on the irreparable elastic zone to weakening of the bone in the zone of irreparable damage are shown [1].

\section{Method}

This review was conducted in accordance with the Cochrane Collaboration guidelines for systematic reviews and meta-analyses; the PRISMA-statement and GRADE quality assessment were used during drafting of the manuscript.

\section{Eligibility Criteria}

\section{Study types}

The search strategy for this systematic review was limited to randomized controlled (RCT), case-controls and case-series.

\section{Types of patients}

Inclusion was limited to studies on patients under eighteen years with an acute traumatic bowing of the lower arm.

\section{Types of intervention}

Intervention of interest was treatment with closed reduction or conservative with cast only.

\section{Types of outcome}

The primary outcome measure was (I) function, in particular pro and supination of the lower arm. Secondary outcomes were (II) posttraumatic function, (III) post-treatment function and (IV) residual bowing.

\section{Objectives}

To compare literature on the effect of treatment and the functional outcome in children with traumatic bowing fracture of the lower arm.

\section{Data Sources}

Studies were independently selected by 2 reviewers (Linde Musters and Joost Colaris) via a systematic search of electronic databases; Embase, Medline, Web of Science, Scopus, Cochrane, Pubmed publisher, CINAHL and Google scholar. All were last accessed at the 15th of May 2016 (Table 1). The reference lists of included articles were utilized to maximize search sensitivity. Only published articles were reviewed. Abstracts from meetings, letters to the editor, unpublished reports and review articles were excluded. All languages were considered, if translation was possible.

\begin{tabular}{|l|l|l|}
\hline Embase.com & 1040 & 1022 \\
\hline Medline Ovid & 685 & 83 \\
\hline Web of science & 194 & 46 \\
\hline Scopus & 455 & 42 \\
\hline Cochrane & 14 & 1 \\
\hline Pubmed publisher & 16 & 7 \\
\hline CINAHL(EBSCOhost) & 61 & 6 \\
\hline Google scholar & 128 & 73 \\
\hline Total & 2593 & 1280 \\
\hline
\end{tabular}

Table 1: Data sources.

\section{Study Selection and Data Extraction}

Two reviewers (Linde Musters and Joost Colaris) independently screened all retrieved studies based on title and abstract. This selection 
Citation: Musters L, Colaris J (2017) Systematic Review on the Functional Outcome After Treatment of a Traumatic Bowing Fracture of the

Page 3 of 7

yielded 21 articles which met the inclusion criteria, consisting of age $<18 \mathrm{yr}$, traumatic bowing of the forearm (ulna, radius or both), treatment existing of conservative, cast or closed reduction and cast. Exclusion criteria are; age $\geq 18 \mathrm{yr}$, radial head fracture or dislocation (Monteggia facture), no trauma, ORIF or CRIF.

In case of disagreement, a third party (JC) was consulted. Finally, five articles were usable to assimilate (Figure 4).

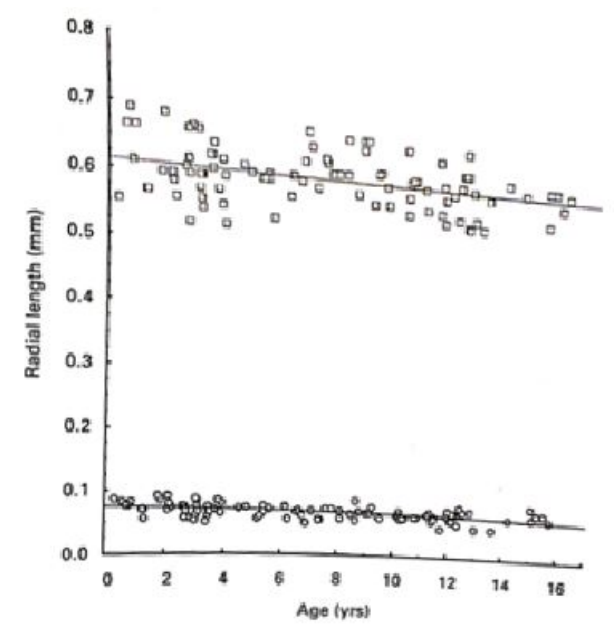

Figure 4: Measure method for bowing of the radius validated in 2004 for children, derivate from the method of Schemitsch en Richards $\nabla$ point of maximal bowing, $x / y \times 100=60.39 \%$, ○ maximal radial bowing, $\mathrm{r} / \mathrm{y} \times 100=7.21$.

\section{Risk of bias assessment}

Two authors (Linde Musters and Joost Colaris) independently assessed methodological quality of the included studies. This critical step in the review process evaluates the risk of bias; the risk of bias assessment was performed with use of the Cochrane risk of bias assessment tool. Results are summarized in Table 2 [6].

\begin{tabular}{|l|l|}
\hline Item (+/-/?) & All articles $>\mathbf{5}$ cases \\
\hline $\begin{array}{l}\text { 1. Is this study based on a clearly } \\
\text { defined group of patients which is } \\
\text { determined on the same time in the } \\
\text { course of the disease? }\end{array}$ & $\begin{array}{l}\text { bowing of the ulnar/radial bone/both, } \\
\text { acute posttraumatic }<1 \text { week }>\text { yes } \\
+/ \text { no- }\end{array}$ \\
\hline $\begin{array}{l}\text { 2. Is the follow up sufficiently } \\
\text { complete? }\end{array}$ & $\begin{array}{l}\leq 5 \text { patients, } 80 \text { percent follow up->yes } \\
+/ \text { no- }\end{array}$ \\
\hline $\begin{array}{l}\text { Outcome(s) } \\
\text { 3. Are the outcomes of the study } \\
\text { explicit and objectively disclosed? }\end{array}$ & $\begin{array}{l}\text { function in pro or supination, through } \\
\text { DASH or function tool, pain->yes+/no- }\end{array}$ \\
\hline $\begin{array}{l}\text { 4. Is the measure of the outcome(s) } \\
\text { valid and reliable? }\end{array}$ & $x$ \\
\hline $\begin{array}{l}\text { 5. Are the outcome(s) independently } \\
\text { (blindly) set? }\end{array}$ & $\begin{array}{l}\text { amount of degrees with goniometer- } \\
>\text { yes+/no- }\end{array}$ \\
\hline Prognostic & $x$ \\
\hline $\begin{array}{l}\text { 6. Are the prognostic factors explicitly } \\
\text { and objectively disclosed? }\end{array}$ & \\
\hline
\end{tabular}

\begin{tabular}{|l|l|}
\hline $\begin{array}{l}\text { 7. Is follow up available of an enough } \\
\text { proportionate group of the included } \\
\text { patients? }\end{array}$ & $\begin{array}{l}\text { long term follow up }>6 \text { months->yes } \\
+/ \text { no- }\end{array}$ \\
\hline $\begin{array}{l}\text { 8. Is the measure of the prognostic } \\
\text { factors of all patients implemented the } \\
\text { same way? }\end{array}$ & $\begin{array}{l}\text { amount of degrees according to } \\
\text { measure method of Schemitsch and } \\
\text { Richards->yes+/no- }\end{array}$ \\
\hline $\begin{array}{l}\text { 9. Is the measure of the prognostic } \\
\text { factors valid and reliable? }\end{array}$ & $\begin{array}{l}\text { reference to article of Schemitsch and } \\
\text { Richards->yes+/no- }\end{array}$ \\
\hline $\begin{array}{l}\text { 10. Is the measure of the prognostic } \\
\text { factors available of an enough } \\
\text { proportionate group of the included } \\
\text { patients? }\end{array}$ & $x$ \\
\hline
\end{tabular}

Table 2: Risk of bias assessment by Cochrane.

\section{Results}

\section{Included studies}

Search on Embase, Medline, Web of Science, Scopus, Cochrane, Pubmed publisher, CINAHL and Google scholar provided 2593 articles. After removing duplicates 1280 articles remained. Based on its title and abstract, 21 article abstracts were retrieved in full text and reviewed in duplicate (Linde Musters and Joost Colaris). Sixteen of these articles did not meet the inclusion criteria. The remaining five articles were included in the review, four case series and one prospective cohort study (Figure 5).

Study characteristics are shown in Table 1. Studies were performed in Belgium and America between 1974-2003. A total of sixty patients were included. $24(40 \%)$ female, $28(47 \%)$ male and 8 (13\%) with unknown gender. Mean age was 8.3 years. Twenty-five (42\%) children sustained an isolated ulna bowing, $16(27 \%)$ an isolated radial bowing and $19(32 \%)$ a bowing of both long bones in the lower arm [1-3,7,8].

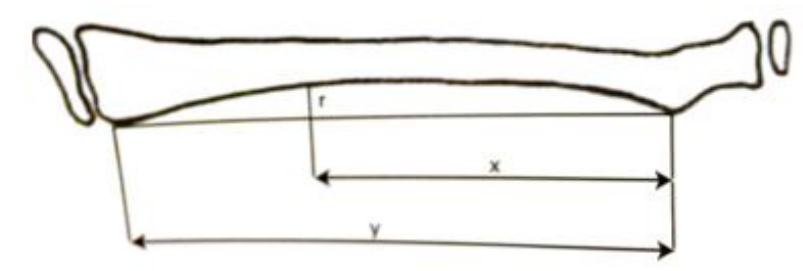

Figure 5: AP X-ray of the radial bone; (y) length of the radius, measured from the biceps tuberosity-radioulnar joint, (x) maximum distance of the radius from the maximal bowing, (r) distance of the maximal bowing till the y line.

\section{Outcomes measures}

Four out of five studies (80\%) cover our main outcome measure, pro- and supination after treatment $[1,2,7,8]$. Half of these studies also describes the direct posttraumatic function in degrees function loss in pro or supination $[2,8]$.

Four out of the five studies $80 \%$ describe the type of treatment, variating between closed reduction alone, closed reduction followed by 
four to eight weeks of immobilization by a cast or only four to eight weeks of immobilization.

Furthermore four of the five (80\%) studies describe the amount of bowing in degrees posttraumatic and the remaining bowing after treatment.

Three out of five studies (60\%) are in favour of reduction to decrees function loss. Borden 1975 describes a persisting loss of function after a bowing fracture, when no reduction is attempted. Sanders et al, describes a faster and better function after reduction compared to no reduction cases in the literature. And finally, Vorlat et al. advices reduction at an earlier age $>6$ years and $>10$ degrees of bowing/loss of function.

\section{Discussion}

No previous systematic overview in literature has been written on traumatic bowing of the lower arm in children to our knowledge. We found that there is a weight of evidence in favor of treatment of traumatic bowing by reduction having a beneficial effect on the outcome.

However, the included studies in this review had several limitations. All populations were small numbers variating between eight and seventeen patients. The type of studies were mostly case reports or case series. Furthermore, the majority of the available articles were not recent and dated.

The amount of bowing in degrees was not documented by Borden in 1975 and Crowe, and scarcely by the three other studies. Furthermore, the posttraumatic function in degrees of pronation and supination was only documented by Borden in 1974. Type of treatment was not reported by Crowe, the other studies all describe different types of treatments. The mechanism of reduction seems similar, but the duration of immobilization by cast varies. Furthermore, the amount of residual bowing after treatment is incompletely documented, by the majority of the studies. The same accounts for the incomplete documentation of functional outcome, which was listed as "incomplete", but was also documented as "limited" or "100\%". The limited function is not split in the amount of pronation and supination loss.

Three studies have extensive follow up variating between two and 157 weeks, Borden in 1974 and Crowe do not report any follow up. This lack of information renders it difficult to make statements on the effect of residual bowing and functional outcome and on the beneficial effect of the different treatment strategies.

This review was conducted in accordance with the Cochrane Collaboration guidelines for systematic reviews and meta-analyses; the PRISMA-statement and GRADE quality assessment were used during drafting of the manuscript. Nonetheless, only 5 articles were suitable for inclusion with all small sample sizes variating between eight and seventeen patients. A lot of data is lacking, but attempts to uncover these data all failed, due to the long period since the publication of these articles, the authors were all unattainable.

The current incidence of plastic deformity of the lower arm in children is probably higher than currently estimated, because 25 percent of the cases is discovered during treatment for other lesions of the arms [8]. Several reasons for the low detection of this diagnosis are; difficultly of the interpretation of the deformities on standardized X- rays, insufficient knowledge on the possibility of the diagnosis under doctors in the emergency room and an ambiguous presentation.

Borden et al. is the first to describe this plastic deformation of the lower arm in children in the literature [1]. This hypothesis was confirmed by the principle of plastic deformation of long bones in in vivo and in vitro animal experiments [4]. These studies concluded that the long bones of children have a different force-formation curve (Figure 3) compared to adults. When a force of $100 \%$ to $150 \%$ of bodyweight is supplied of both ends of the bone, micro fractures appear on the concave side of the bowing, leading to a plastic deformity. Bowing of the bone causes a minimal hemorrhage in the periosteum of the entire diaphysis. This leads to a late radiologic finding of mild cortical broadening on the concave side of the bowing, without any callus, usually 4 months to 6 months after trauma [8].

There are three types of bowing fractures of the lower arm in children; (i) Bowing of one long bone and a greenstick of the other, (ii) bowing of both long bones, (iii) bowing of the ulna with a radial head fracture or luxation (Monteggia).

It is recommended to measure the bowing using them in 2004 validated measure method of Firl [5] (Figure 6). When the bowing exceeds 7.21 percent, a bowing fracture should be considered (Figure 4). Literature shows that 60 cases of bowing have been described, which were included for this review, 25 of these children had an isolated ulna bowing, 16 an isolated radial bowing and 19 bowing of both long bones. All groups are small (max cases), and therefore no significant statements can be done concerning; the effect of type of treatment on the primary outcome (pro or supination loss and residual bowing).

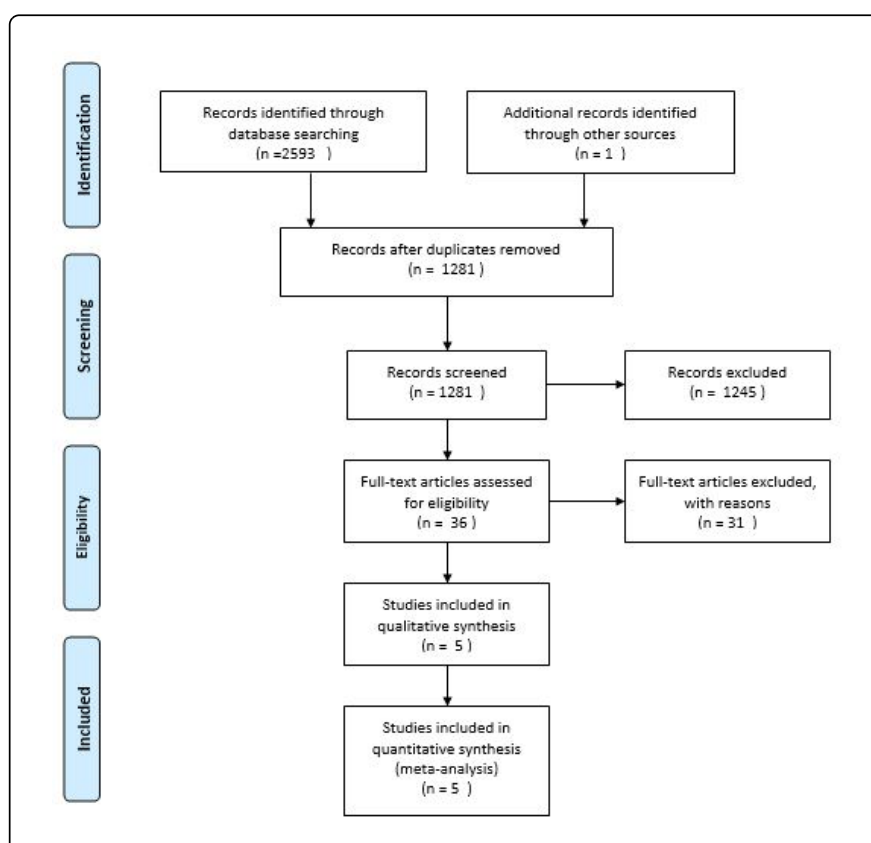

Figure 6: PRISMA 2009 flow diagram.

Four of the five studies (80\%) cover our main outcome measure, pro- and supination after treatment $[1,2,7,8]$. Half of the studies also describes the direct posttraumatic function in degrees of function loss of pro or supination [2,8]. These values variate between 15 and 30 degrees supination loss. Two articles describe limited pro or 
Citation: Musters L, Colaris J (2017) Systematic Review on the Functional Outcome After Treatment of a Traumatic Bowing Fracture of the

Page 5 of 7

supination, without specification in degrees [3,7]. Results do show that 25 children (42 percent) had a persisting pronation or supination limitation at follow-up.
There were three different types of treatment; (i) reduction only, (ii) reduction followed by minimal four to maximal eight weeks of cast or (iii) four to eight weeks cast only (Table 3 ).

\begin{tabular}{|c|c|c|c|c|c|c|c|c|c|c|c|c|c|c|}
\hline Author & Year & Country & Type & Amount & & Population & & Outcome & & & & & & \\
\hline & & & & & Sex & $\begin{array}{l}\text { Age (yr/ } \\
\text { months) }\end{array}$ & $\begin{array}{l}\text { Bone } \\
\text { bowed }\end{array}$ & Type & $\begin{array}{l}\# \\
\text { degree } \\
\mathrm{s} \text { of } \\
\text { bowing }\end{array}$ & $\begin{array}{l}\text { Function } \\
\text { posttraumati } \\
\text { c }\end{array}$ & $\begin{array}{l}\text { Treatmen } \\
\mathrm{t}\end{array}$ & $\begin{array}{l}\text { \# } \\
\text { degrees } \\
\text { bowing } \\
\text { after } \\
\text { treatment }\end{array}$ & $\begin{array}{l}\text { FU } \\
\text { (weeks } \\
\text { ) }\end{array}$ & $\begin{array}{l}\text { Functio } \\
\mathrm{n}\end{array}$ \\
\hline \multirow[t]{4}{*}{ Borden } & \multirow[t]{4}{*}{1974} & \multirow[t]{4}{*}{ USA } & \multirow[t]{4}{*}{$\begin{array}{l}\text { Case } \\
\text { series }\end{array}$} & \multirow[t]{4}{*}{8} & $\mathrm{~F}$ & 2.4 & Ulna & \multirow[t]{4}{*}{$\begin{array}{l}\text { degrees, } \\
\mathrm{P} / \mathrm{S}\end{array}$} & 7 & $\begin{array}{l}30 \text { degrees } \\
\text { sup loss }\end{array}$ & $\begin{array}{ll}\text { cast } & 3 \\
\text { weeks } & \end{array}$ & 7 & 65 & $100 \%$ \\
\hline & & & & & $M$ & 8.8 & Both & & $\begin{array}{l}\text { R20/ } \\
\text { U13 }\end{array}$ & $?$ & $\begin{array}{l}\text { reduction } \\
+ \text { cast } 3 \\
\text { weeks }\end{array}$ & R5/U0 & 3 & $100 \%$ \\
\hline & & & & & $M$ & 11.4 & Both & & $\begin{array}{l}\text { R17/ } \\
\text { U14 }\end{array}$ & $\begin{array}{l}15 \text { degreees } \\
\text { sup loss }\end{array}$ & reduction & $\mathrm{R} 0 / \mathrm{U} 4$ & 12 & $100 \%$ \\
\hline & & & & & $4 \mathrm{~F} / 1 \mathrm{M}$ & $6.4-13.8$ & $3 R / 2 U$ & & $?$ & limited & reduction & $?$ & no & limited \\
\hline Borden & 1975 & USA & $\begin{array}{l}\text { Case } \\
\text { series }\end{array}$ & 17 & $9 \mathrm{~F} / 8 \mathrm{M}$ & $2.0-11.5$ & $\begin{array}{l}5 \mathrm{R} / 8 \mathrm{U} / \\
\text { 4both }\end{array}$ & $\begin{array}{l}\text { degrees, } \\
\text { P/S }\end{array}$ & $?$ & $?$ & no & $?$ & no & $?$ \\
\hline \multirow[t]{5}{*}{ Crowe } & \multirow[t]{5}{*}{1977} & \multirow[t]{5}{*}{ USA } & \multirow[t]{5}{*}{$\begin{array}{l}\text { Case } \\
\text { series }\end{array}$} & \multirow[t]{5}{*}{11} & & $3.0-14.0$ & $\begin{array}{l}3 \mathrm{R} / 3 \mathrm{U} / \\
5 \text { both }\end{array}$ & $?$ & $?$ & $?$ & $?$ & $?$ & $?$ & $?$ \\
\hline & & & & & $\mathrm{F}$ & 9 & Radius & $?$ & $?$ & $?$ & $?$ & $?$ & $?$ & $?$ \\
\hline & & & & & $M$ & 7 & Ulna & $?$ & $?$ & $?$ & $?$ & $?$ & $?$ & $?$ \\
\hline & & & & & $\mathrm{F}$ & 5 & Both & $?$ & $?$ & $?$ & $?$ & $?$ & $?$ & $?$ \\
\hline & & & & & $?$ & $?$ & $\begin{array}{l}\text { 2R/2U/ } \\
\text { 4both }\end{array}$ & $?$ & $?$ & $?$ & $?$ & $?$ & $?$ & $?$ \\
\hline \multirow[t]{14}{*}{$\begin{array}{l}\text { Sander } \\
\text { s }\end{array}$} & \multirow[t]{14}{*}{1983} & \multirow[t]{14}{*}{ USA } & \multirow[t]{14}{*}{$\begin{array}{l}\text { Prospectiv } \\
\text { e cohort }\end{array}$} & \multirow[t]{14}{*}{13} & $7 \mathrm{M} / 6 \mathrm{~F}$ & $4.0-15.0$ & $\begin{array}{ll}2 \mathrm{R} / & 5 \mathrm{U} / \\
\text { 6both } & \end{array}$ & \multirow{14}{*}{$\begin{array}{l}\text { degrees, } \\
\text { P/S, } \\
\text { reduction } \\
\text {, X-ray }\end{array}$} & $?$ & $?$ & & 3,4 & 18 & \\
\hline & & & & & $M$ & 4 & both & & & & no & & 3 & $?$ \\
\hline & & & & & $M$ & 8 & both & & & & reduction & & 12 & $?$ \\
\hline & & & & & $\mathrm{F}$ & 5 & both & & & & no & & 12 & $?$ \\
\hline & & & & & $M$ & 5 & both & & $\begin{array}{l}\text { R15/ } \\
\text { U15 }\end{array}$ & & reduction & R5/ U4 & 18 & $?$ \\
\hline & & & & & $M$ & 7 & both & & $\begin{array}{l}\text { R20/ } \\
\text { U15 }\end{array}$ & & reduction & R6/ U9 & 12 & $100 \%$ \\
\hline & & & & & $M$ & 8 & both & & $\begin{array}{l}\text { U25/ } \\
\text { R? }\end{array}$ & & reduction & U18 & 4 & $?$ \\
\hline & & & & & $F$ & 10 & Radius & & 10 & & reduction & 0 & 4 & $?$ \\
\hline & & & & & $F$ & 10 & Radius & & 16 & & $\begin{array}{l}\text { reduction } \\
+ \text { cast } 6 \\
\text { weeks }\end{array}$ & 0 & 3 & $100 \%$ \\
\hline & & & & & $\mathrm{F}$ & 6 & Ulna & & 30 & & reduction & 16 & 2 & $?$ \\
\hline & & & & & M & 6 & Ulna & & 35 & & reduction & 15 & 0 & $?$ \\
\hline & & & & & $\mathrm{F}$ & 8 & Ulna & & & & reduction & & 6 & $100 \%$ \\
\hline & & & & & $\mathrm{F}$ & 6 & Ulna & & & & no & & 0 & $?$ \\
\hline & & & & & $M$ & 15 & Ulna & & 22 & & reduction & 11 & 6 & $?$ \\
\hline
\end{tabular}


Citation: Musters L, Colaris J (2017) Systematic Review on the Functional Outcome After Treatment of a Traumatic Bowing Fracture of the

Page 6 of 7

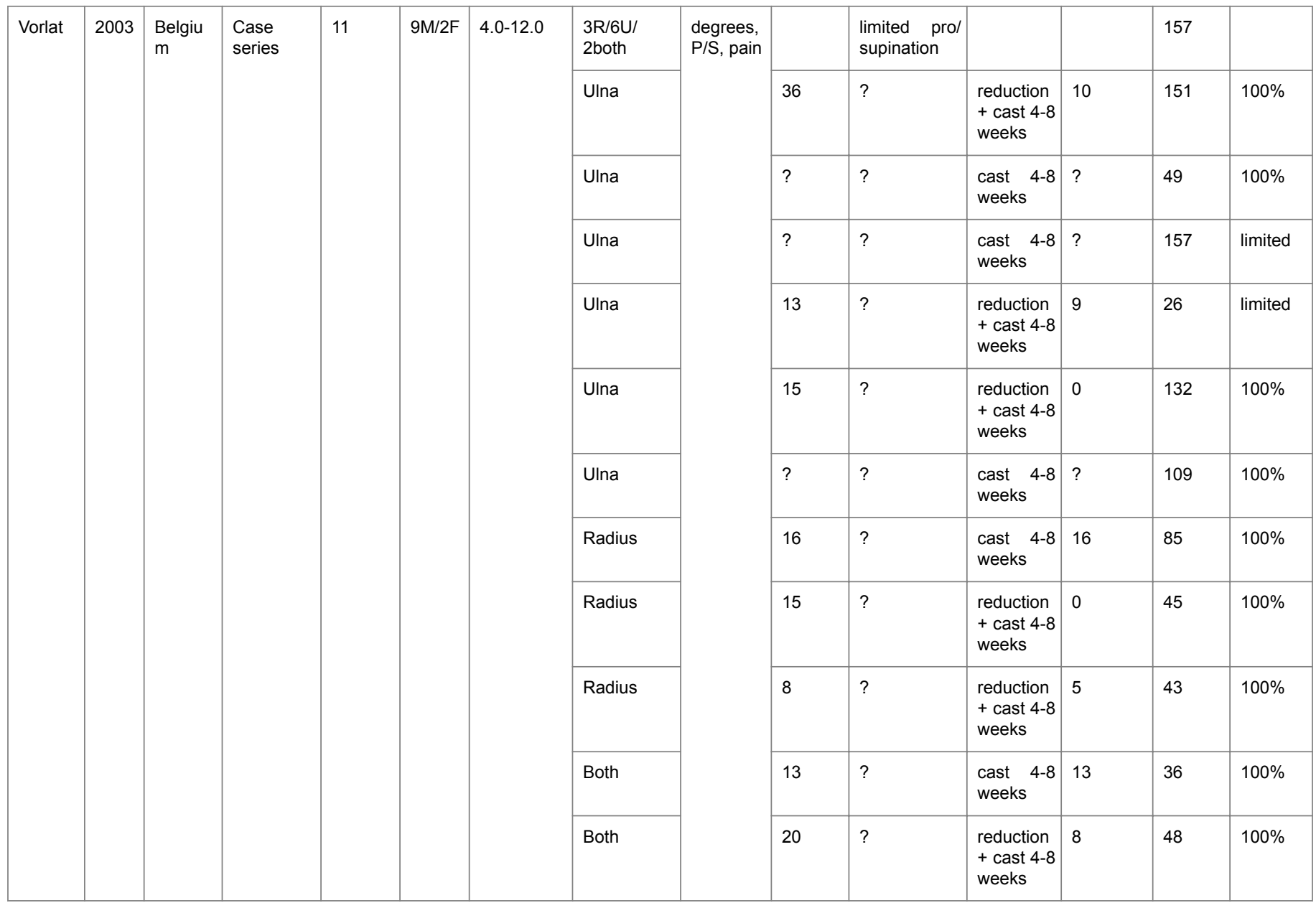

Table 3: Overview of data of the included articles.

Treatment by closed reduction showed a normal function at followup. When treated with four to eight weeks of cast a residual loss in function is seen variating between zero and 25 degrees of pronation loss. Treatment with reduction followed by cast also shows a remaining function loss between zero and 20 degrees of pronation loss.

Four out of five articles ( $80 \%$ describe the posttraumatic residual bowing in degrees and half of these studies also describe the residual bowing in degrees after treatment.
The average posttraumatic ulnar bowing is 20 degrees, the average posttraumatic radial bowing is fifteen points two degrees. The average residual ulnar bowing after treatment is eight points six degrees, the average residual radial bowing is four points one degrees (Table 4). All show a clear decrease in bowing after treatment. The treatment was overall well tolerated, had a direct effect and lead to faster restore of function [8].

\begin{tabular}{|l|l|l|l|}
\hline \multicolumn{2}{|l|}{ Posttraumatic bowing (in degrees) } & \multicolumn{2}{l|}{ Residual bowing after treatment (in degrees) } \\
\hline ulna & $(7+13+14+15+15+25+30+35+22+36+13+15) / 12=20$ & ulna & $(7+0+4+4+9+18+16+15+11+10+9+0) / 12=8.6$ \\
\hline radius & $(20+17+15+20+10+16+16+15+8) / 9=15.2$ & radius & $(5+0+5+6+0+0+16+0+5) / 9=4.1$ \\
\hline
\end{tabular}

Table 4: Calculation of average bowing in degrees.

There is no protocol for treatment of plastic deformity of the lower arm in children, but there is consensus in literature concerning children $<$ four years of age. Literature states that these children can be treated conservatively with cast, unless bowing exceeds 20 degrees, then reduction is advised. On the main group age four to ten years, no consensus has been reached. In the available literature altering advises are described, variating from conservative treatment, reduction when $>20$ degrees to reduction only when limited function is present at presentation [8]. The group of children over ten years of age has less remodeling potential, and, therefore the consensus is that all bowings more than ten degrees necessitate reduction for optimal functional outcomes [2]. Furthermore, reduction is always advised when the 
Citation: Musters L, Colaris J (2017) Systematic Review on the Functional Outcome After Treatment of a Traumatic Bowing Fracture of the

bowing of one long bone complicates reduction of the other long bone. It is unclear to what amount of solitary bowing can be accepted without any loss of function. But in view of the low risk of complications and good results after reduction, the overall opinion is to reduce all significant bowing fractures of the lower arm in children with limited function [8].

Ideally a randomized controlled trial should be initiated, in which two groups of reduction versus non-reduction are being compared. One group with reduction followed by cast and one group with only cast, corrected for the degrees of bowing and age of the patient. This might aid in the determination of the optimal treatment policy is depending on age and severety of bowing. Unfortunately, this is hard to facilitate, mainly because of the scarce knowledge on the topic by treating physicians and low incidence. Hopefully this review will give prominence to this diagnosis, which will facilitate prospective studies in the future.

\section{Conclusion}

Traumatic bowing of the lower arm in children is currently underexposed and frequently missed. It is a difficult diagnosis due to scarce knowledge under doctors in the emergency room, an ambiguous presentation and late visibility on standardized X-rays. A possible late radiologic finding is a mild cortical broadening on the concave side of the bowing, without any callus, usually four to six months after trauma [8] (Figure 2). This plastic deformity of the lower arm can give distinctive function loss, by decrease in pro or supination when not treated properly. Treatment consists of reduction under general anesthetics by exerting force with $100 \%$ to $150 \%$ of the patient's body weight on both ends of the long bone for a few minutes. This leads to a direct radiological result and an improvement of function, by increase in pro or supination. Reduction is well accepted by patients, therefore when the bowing of the radius exceeds seven points twentyone percent, reduction should be considered as a treatment option [5]. Hopefully this article will lead to a better awareness of this diagnosis so adequate treatment will follow and function loss can be prevented.

\section{Acknowledgement}

Jasmijn W Selten, Department of Surgery, Erasmus MC- University Medical Centre, Rotterdam, Netherlands and W. Bramer, Biomedical Information specialist, Erasmus MC- University Medical Centre, Rotterdam, Netherlands.

\section{References}

1. Borden S (1974) Traumatic bowing of the forearm in children. J Bone Joint Surg Am 56: 611-616.

2. Vorlat P, De Boeck H (2003) Bowing fractures of the forearm in children: a long-term follow-up. Clin Orthop Relat Res 233-237.

3. Crowe JE, Swischuk LE (1977) Acute bowing fractures of the forearm in children: a frequently missed injury. AJR Am J Roentgenol 128: 981-984.

4. Chamay A (1970) Mechanical and morphological aspects of experimental overload and fatigue in bone. J Biomech 3: 263-270.

5. Firl M, Wünsch L (2004) Measurement of bowing of the radius. J Bone Joint Surg Br 86: 1047-1049.

6. http://netherlands.cochrane.org/beoordelingsformulieren-en-anderedownloads

7. Borden S (1975) Roentgen recognition of acute plastic bowing of the forearm in children. Am J Roentgenol Radium Ther Nucl Med 125: 524-530.

8. Sanders WE, Heckman JD (1984) Traumatic plastic deformation of the radius and ulna. A closed method of correction of deformity. Clin Orthop Relat Res 58-67. 